\title{
Treatment of a severe Class II malocclusion with pre-existing root resorption \\ - A judicious use of orthodontic appliances
}

SADJ April 2021, Vol. 76 No. 3 p142 - p146

I Hansa

\section{CASE REPORT}

The orthodontic treatment of patients with pre-existing root resorption $(R R)$ is often difficult due to the increased risk of progression and often a compromised treatment outcome can be expected..$^{1,2}$

The treatment plan in such situations should comprise of a root sparing strategy, which includes reducing the treatment duration with fixed appliances, non-extraction treatment, reducing force levels, avoiding intrusion of at-risk teeth, reducing the amount of apical movement of the affected teeth and intermittent force application where possible. ${ }^{1-6}$

The following case report shows the use of a root sparing strategy in the treatment of a severe Class II malocclusion with pre-existing root resorption of the 11 and 21 .

\section{DIAGNOSIS AND TREATMENT PLAN}

A 13-year-old female presented with a chief complaint of protrusive upper anterior teeth (Figure 1). She exhibited a convex profile with incompetent lips, an everted lower lip, deep labio-mental sulcus and a mild mandibular deviation to the right. An Angle Class II, division 1 relationship on a Class II skeletal base was observed, with an overjet and overbite of $13 \mathrm{~mm}$ and $10 \mathrm{~mm}$ respectively.

The upper arch had minor crowding of $2 \mathrm{~mm}$, and the lower arch had moderate crowding of $5 \mathrm{~mm}$, in addition to a $6 \mathrm{~mm}$ curve of Spee. The upper midline was coincident with the facial midline, and the lower midline was $4 \mathrm{~mm}$ to the right of the facial midline.

Furthermore, there was a reverse crossbite between the 24/34 and high frenal attachments between upper and lower central incisors, with mild recession on the 31 which seemed to be caused by the aformentioned frenal attachment. $^{7}$ A periodontal evaluation was performed and the recession was to be reassessed after orthodontic treatment.

Author affiliations:

Ismaeel Hansa: BDS, MSc, Private Practice, Durban, South Africa. ORCID Number: 0000-0001-6070-4534

Email: drismaeelhansa@gmail.com
The cephalometric analysis (Table 1) found a Class II anteroposterior skeletal relationship (ANB: 5.1; Wits: $7.6 \mathrm{~mm}$ ), and a hypodivergent pattern of growth (SN-GoGn: 25.7; Co-Go-Me: 114.7). The upper incisors were proclined (U1-PP: $\left.127.7^{\circ}\right)$, and the lowers were retroclined ( $\mathrm{L} 1-$ GoGn: $86.6^{\circ}$ ) and retruded (L1-APo: $\left.-2.1 \mathrm{~mm}\right)$. The lower lip was retruded $(-1.5 \mathrm{~mm})$.

Radiographic imaging showed a Grade 4 resorption of the 11, and a Grade 3 resorption of the 21 (Figure 1). ${ }^{8}$

On further investigation, the patient revealed a history of primary upper incisors avulsion due to trauma at age 6 . This may have played a role in triggering the initial resorption.

The treatment objectives included preventing progression of the RR and recession, achieving a Class I molar and canine relationship, obtaining a normal overjet and overbite, resolving the crossbites, leveling, aligning, and coordinating the arches, improving the smile and soft tissue aesthetics, and retaining the results after treatment completion.

\begin{tabular}{|l|l|l|l|l|}
\hline \multicolumn{5}{|c|}{ Table 1. Initial and final cephalometric analysis. } \\
\hline SNA & $81.6^{\circ}$ & $81.4^{\circ}$ & $-0.2^{\circ}$ & $82^{\circ}$ \\
\hline SNB & $76.5^{\circ}$ & $78.5^{\circ}$ & $2^{\circ}$ & $80^{\circ}$ \\
\hline ANB & $5.1^{\circ}$ & $2.9^{\circ}$ & $-2.2^{\circ}$ & $2^{\circ}$ \\
\hline WITS & $7.6 \mathrm{~mm}$ & $1.8 \mathrm{~mm}$ & $-5.8 \mathrm{~mm}$ & $0 \mathrm{~mm}$ \\
\hline SN-PP & $10.1^{\circ}$ & $7.8^{\circ}$ & $-2.3^{\circ}$ & $8^{\circ}$ \\
\hline SN-GoGn & $25.7^{\circ}$ & $26.4^{\circ}$ & $0.7^{\circ}$ & $33^{\circ}$ \\
\hline PP-GoGn & $15.6^{\circ}$ & $18.6^{\circ}$ & $3^{\circ}$ & $25^{\circ}$ \\
\hline Y axis & $64.2^{\circ}$ & $64^{\circ}$ & $-0.2^{\circ}$ & $61^{\circ}$ \\
\hline U1-PP & $127.7^{\circ}$ & $115.4^{\circ}$ & $-12.3^{\circ}$ & $110^{\circ}$ \\
\hline L1-GoGn & $86.6^{\circ}$ & $103.0^{\circ}$ & $16.4^{\circ}$ & $94^{\circ}$ \\
\hline L1-APo & $-4.4 \mathrm{~mm}$ & $2.5 \mathrm{~mm}$ & $6.9 \mathrm{~mm}$ & $2 \mathrm{~mm}$ \\
\hline Overjet (cast) & $13 \mathrm{~mm}$ & $3 \mathrm{~mm}$ & $10 \mathrm{~mm}$ & $3.5 \mathrm{~mm}$ \\
\hline Overbite (cast) & $10 \mathrm{~mm}$ & $3 \mathrm{~mm}$ & $7 \mathrm{~mm}$ & $2 \mathrm{~mm}$ \\
\hline U1-L1 & $130.1^{\circ}$ & $123.0^{\circ}$ & $-7.1^{\circ}$ & $132^{\circ}$ \\
\hline Naso-labial angle & $99.7^{\circ}$ & $102.9^{\circ}$ & $3.2^{\circ}$ & $102^{\circ}$ \\
\hline Facial convexity & $16.5^{\circ}$ & $8.5^{\circ}$ & $-8^{\circ}$ & $15^{\circ}$ \\
\hline Upper lip protrusion & $6.2 \mathrm{~mm}$ & $3.0 \mathrm{~mm}$ & $-3.2 \mathrm{~mm}$ & $5 \mathrm{~mm}$ \\
\hline Lower lip protrusion & $-1.5 \mathrm{~mm}$ & $1.3 \mathrm{~mm}$ & $2.8 \mathrm{~mm}$ & $4 \mathrm{~mm}$ \\
\hline
\end{tabular}




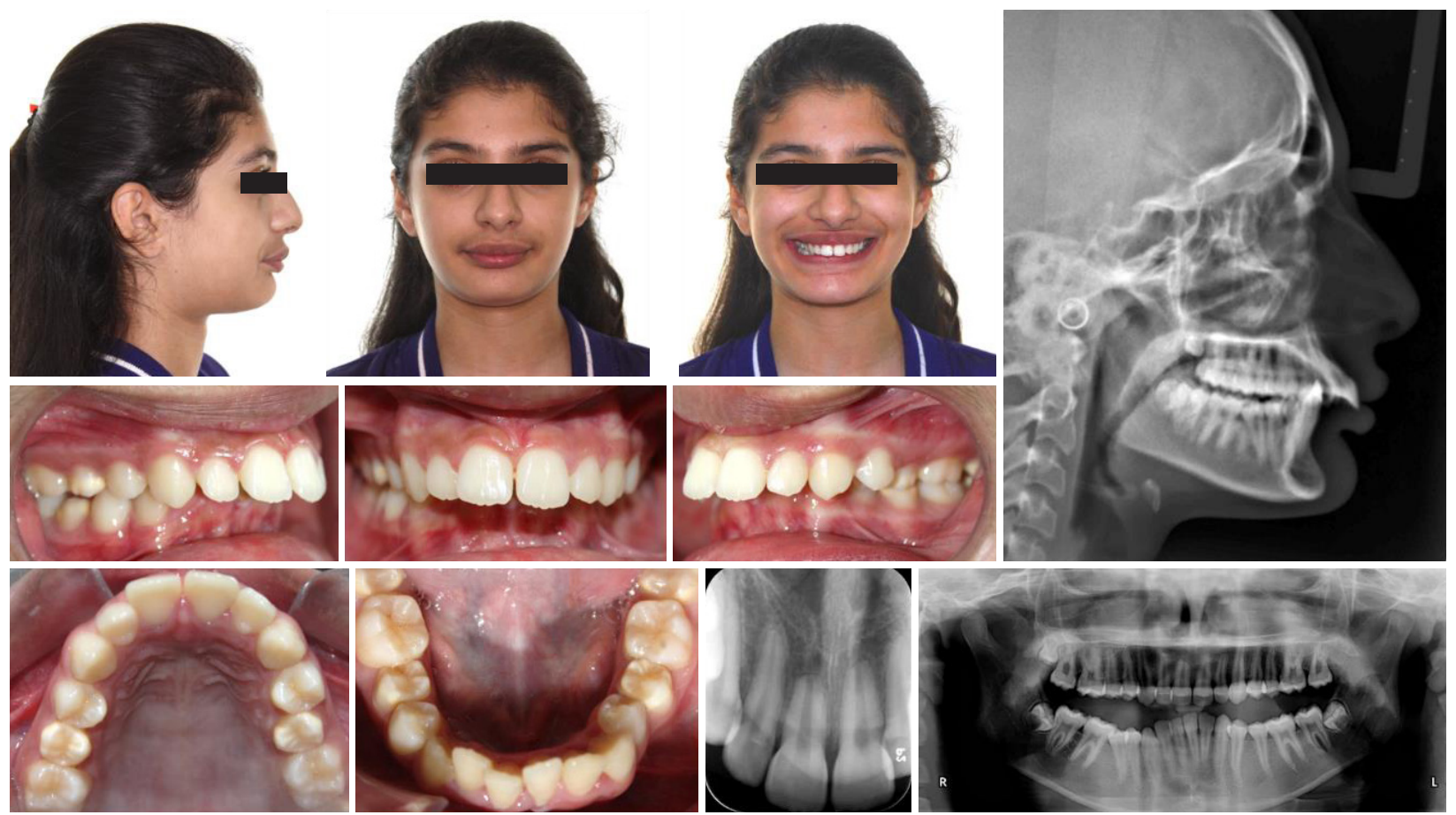

Figure 1. Initial records.
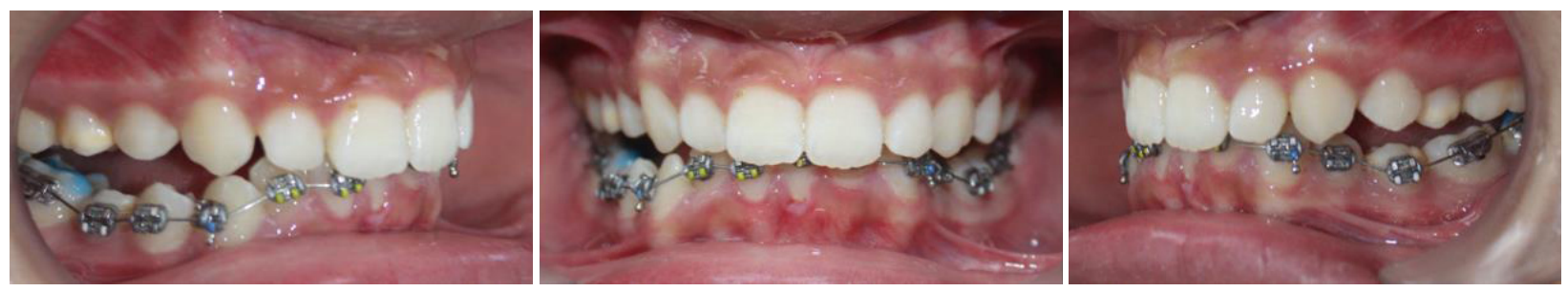

Figure 2. 6-month treatment progress after discontinuation of the twin block, and start of fixed appliance.
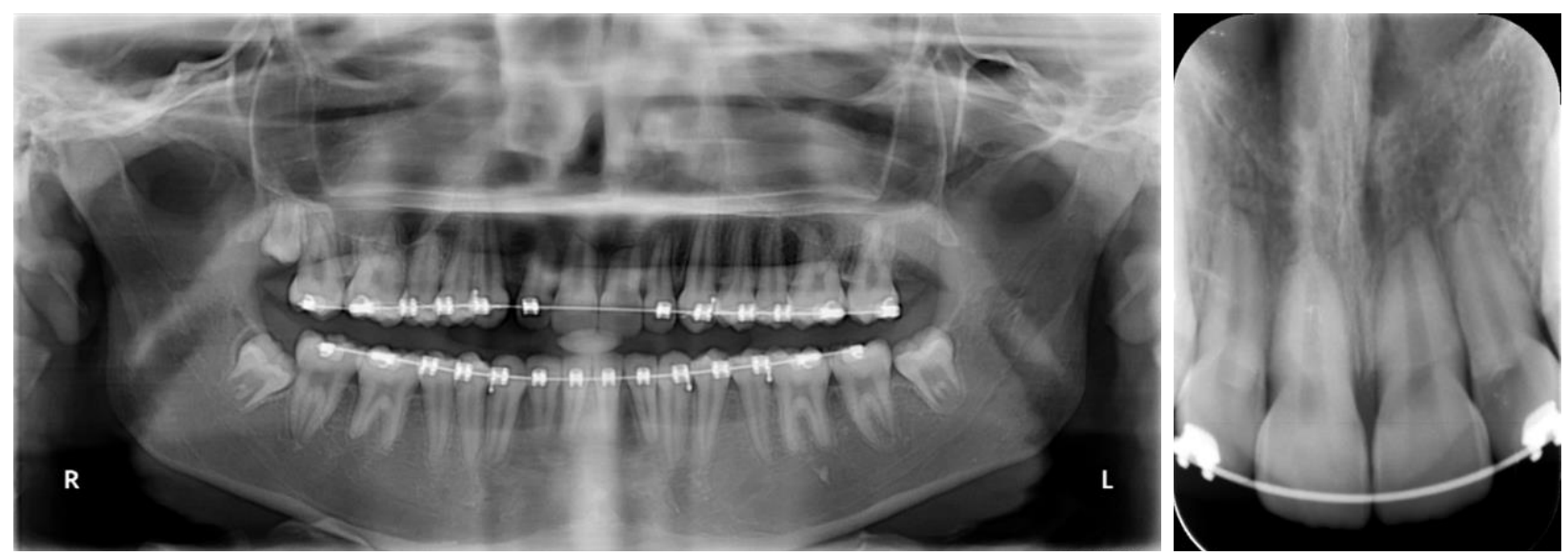

Figure 3. 13-month progress PAN and periapical.
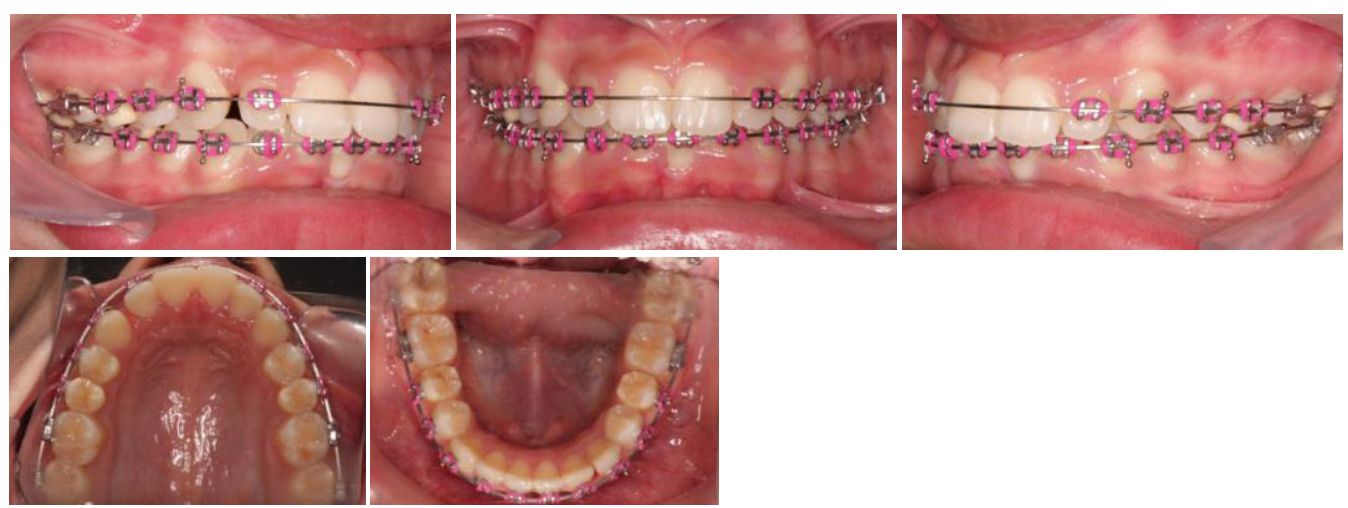

Figure 4. 13-month progress records. 
The treatment plan, which utilized a root sparing strategy, was two-phased and non-extraction. ${ }^{9} \mathrm{~A}$ good prognosis for functional appliance treatment was expected (Co-Go-

Me angle $\left.<125.5^{\circ}\right),{ }^{10}$ and both Herbst and Twin Block appliances were given as options to first correct the sagittal aspect of the malocclusion. ${ }^{11}$ A decision was made to use the twin block as the patient was internally motivated and it seemed that compliance would not be an issue. $^{12}$ Thereafter, fixed preadjusted appliances would be used, however, the 11 and 21 would only be bonded during finishing to prevent further resorption of those teeth. The central incisors were to be monitored every 6 months with a peri-apical radiograph.

\section{TREATMENT PROGRESS}

The twin block appliance with maximum bite advancement was delivered initially with instructions for fulltime wear. ${ }^{13}$ After 6 months, the overjet was $3 \mathrm{~mm}$, and the molars were in a $1 / 2$ cusp Class III relationship, and the decision was made to bond the upper (with exception of the 11 and 21) and lower arches (7-7) to level the lower curve of Spee and align the teeth. (Figure 2) A progress PAN and peri-apical was taken after 13 months of treatment, and the 14 and 34 brackets repositioned (Figure $3 \& 4$ ). The lateral incisors were not repositioned due the resorption seen on the peri-apical. The 11 and 21 were bonded passively to avoid deleterious intrusive forces. Treatment was completed 4 months thereafter (Figure 5). A lower 3-3 fixed lingual retainer was bonded, and an upper wrap-around retainer was delivered.

\section{TREATMENT RESULTS}

The final treatment outcome achieved most of the stated objectives and attained a satisfactory result (Figure 5). Class I molar and canine relationships were obtained, overbite and overjet were reduced to $3 \mathrm{~mm}$, and soft tissue and smile aesthetics were improved. Unfortunately, recession on the 31 increased with treatment and although periodontal treatment was advised, the patient did not
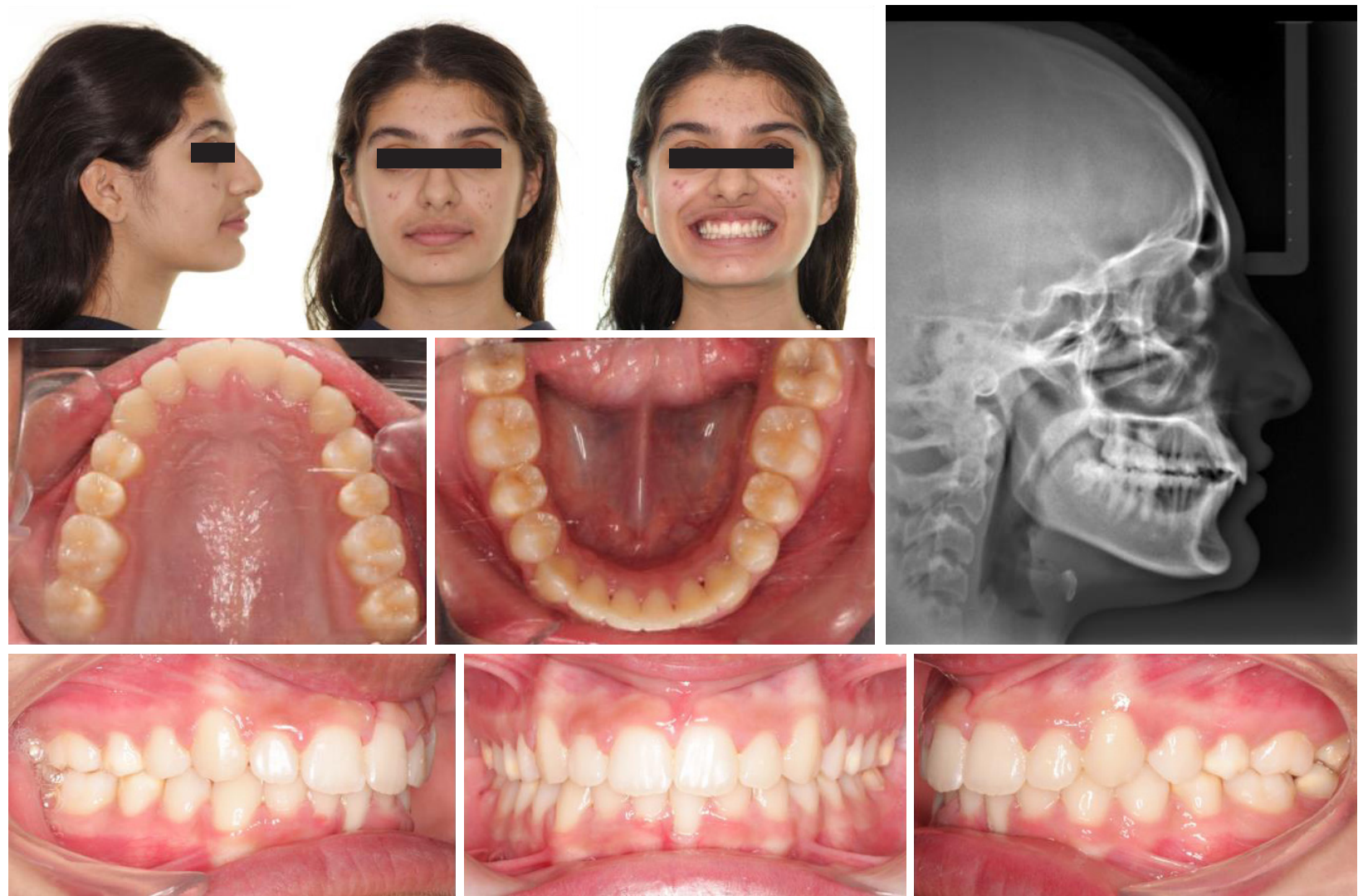

Figure 5. Final records.

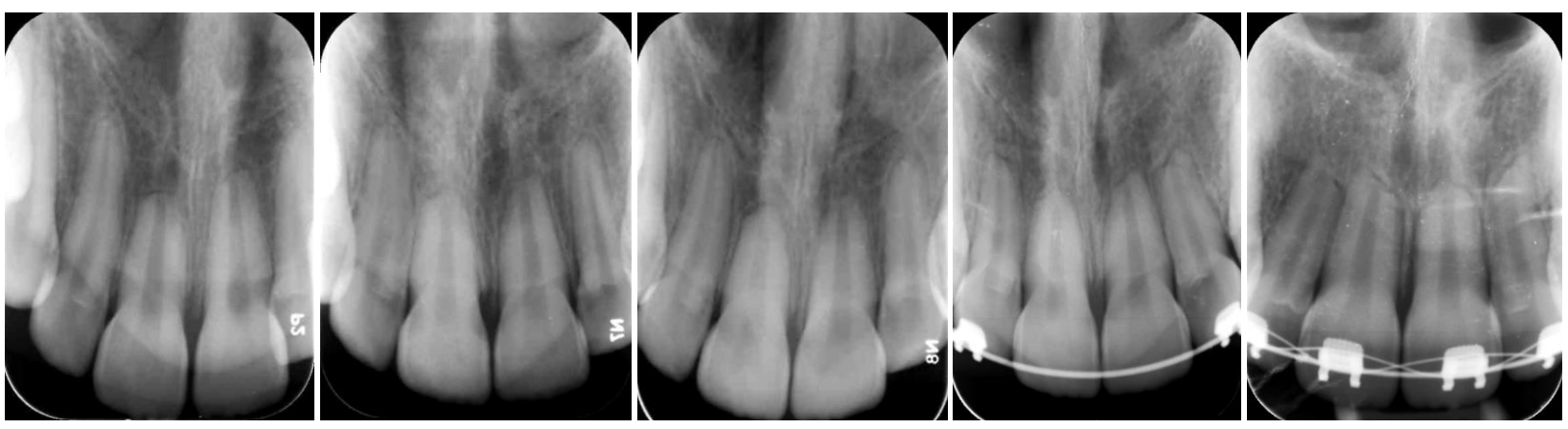

Figure 6. Progression of root resorption at the following time-points: 1) Initial; 2) After 3 months of Twin-block use; 3) After 6 months with the Twin-block and commencement of fixed appliances; 4) After 10 months of fixed appliances; 5) after 18 months of fixed appliances, and 1 month prior to debond. 
want to undergo treatment. There was also mild progression of resorption of the 21 and 11 despite the delayed bonding. The upper lateral incisors also developed a Grade 3 resorption post treatment, suggesting a genetic predisposition (Figure 6). ${ }^{14}$

Post treatment cephalometric changes (Table 1) and superimposition (Figure 7) showed restraint of maxillary growth $\left(-0.2^{\circ}\right)$, and a $2^{\circ}$ increase in SNB. WITS improved from $7.6 \mathrm{~mm}$ to $1.8 \mathrm{~mm}$, probably due to change in occlusal plane and SN-GoGn increased by $0.7^{\circ}$.

The upper incisors retroclined $12.3^{\circ}$, and the lower incisors proclined $16.4^{\circ}$. Although lower incisor proclination has generally not been found to increase gingival recession, ${ }^{15,16}$ our patient had a pre-existing gingival defect, which may have exacerbated the recession. However, adding extra labial root torque to the lower incisors to prevent proclination may well have caused further dehiscence and recession and was thus not performed. ${ }^{17}$ In hindsight, a pretreatment gingival graft may have been indicated. ${ }^{18}$

Facial convexity decreased $8^{\circ}$, the upper lip was retruded by $3.2 \mathrm{~mm}$, and the lower lip protruded $2.8 \mathrm{~mm}$. Unfortunately, no retention records were able to be taken as the patient emigrated two weeks after treatment completion.

\section{DISCUSSION}

The present case shows that the treatment of patients with severe malocclusions and preexisting RR is possible by reducing and eliminating risk factors using a root sparing strategy. Initially, patient related factors should be taken into consideration, such as pre-existing $R R$, incisors with abnormal root morphology and previous trauma. ${ }^{19}$ Thereafter, a root sparing strategy should be planned. This will vary depending on the malocclusion and desired tooth movement. Generally, it would involve the use of light forces, avoiding excessive movement of the tooth apex, using intermittent forces, avoiding intrusion and bodily movement and minimizing the duration in fixed appliances. ${ }^{20}$

\section{References}

1. Roscoe MG, Meira JBC, Cattaneo PM. Association of orthodontic force system and root resorption: A systematic review. Am J Orthod Dentofac Orthop. 2015; 147(5): 610-26. doi:10.1016/j.ajodo.2014.12.026.

2. Weltman B, Vig KWL, Fields HW, Shanker S, Kaizar EE. Root resorption associated with orthodontic tooth movement: A systematic review. Am J Orthod Dentofac Orthop. 2010; 137(4): 462-76. doi:10.1016/j.ajodo.2009.06.021.

3. Maltha JC, van Leeuwen EJ, Dijkman GEHM, KuijpersJagtman AM. Incidence and severity of root resorption in orthodontically moved premolars in dogs. Orthod Craniofacial Res. 2004; 7(2): 115-21. doi:10.1111/j.1601-6343. 2004. 00283.x.

4. Tieu LD, Saltaji H, Normando D, Flores-Mir C. Radiologically determined orthodontically induced external apical root resorption in incisors after non-surgical orthodontic treatment of Class II division 1 malocclusion: a systematic review. Prog Orthod. 2014;15:48. doi:10.1186/s40510-014-0048-7.

5. Motokawa M, Sasamoto T, Kaku M, et al. Association between root resorption incident to orthodontic treatment and treatment factors. Eur J Orthod. 2012; 34(3): 350-6. doi: 10. 1093/ejo/cjr018.

6. Sameshima GT, Sinclair PM. Predicting and preventing root resorption: Part II. Treatment factors. Am J Orthod Dentofac Orthop. 2001; 119(5): 511-5. doi:10.1067.mod.2001.113410.

7. Jati AS, Furquim LZ, Consolaro A. Gingival recession: its causes and types, and the importance of orthodontic treatment. Dental Press J Orthod. 2016; 21(3): 18-29. doi:10.15 90/2177-6709.21.3.018-029.oin.

8. Levander $E$, Malmgren $O$. Evaluation of the risk of root resorption during orthodontic treatment: A study of upper incisors. Eur J Orthod. 1988; 10(1): 30-8. doi:10.1093/ejo/10. 1.30 .
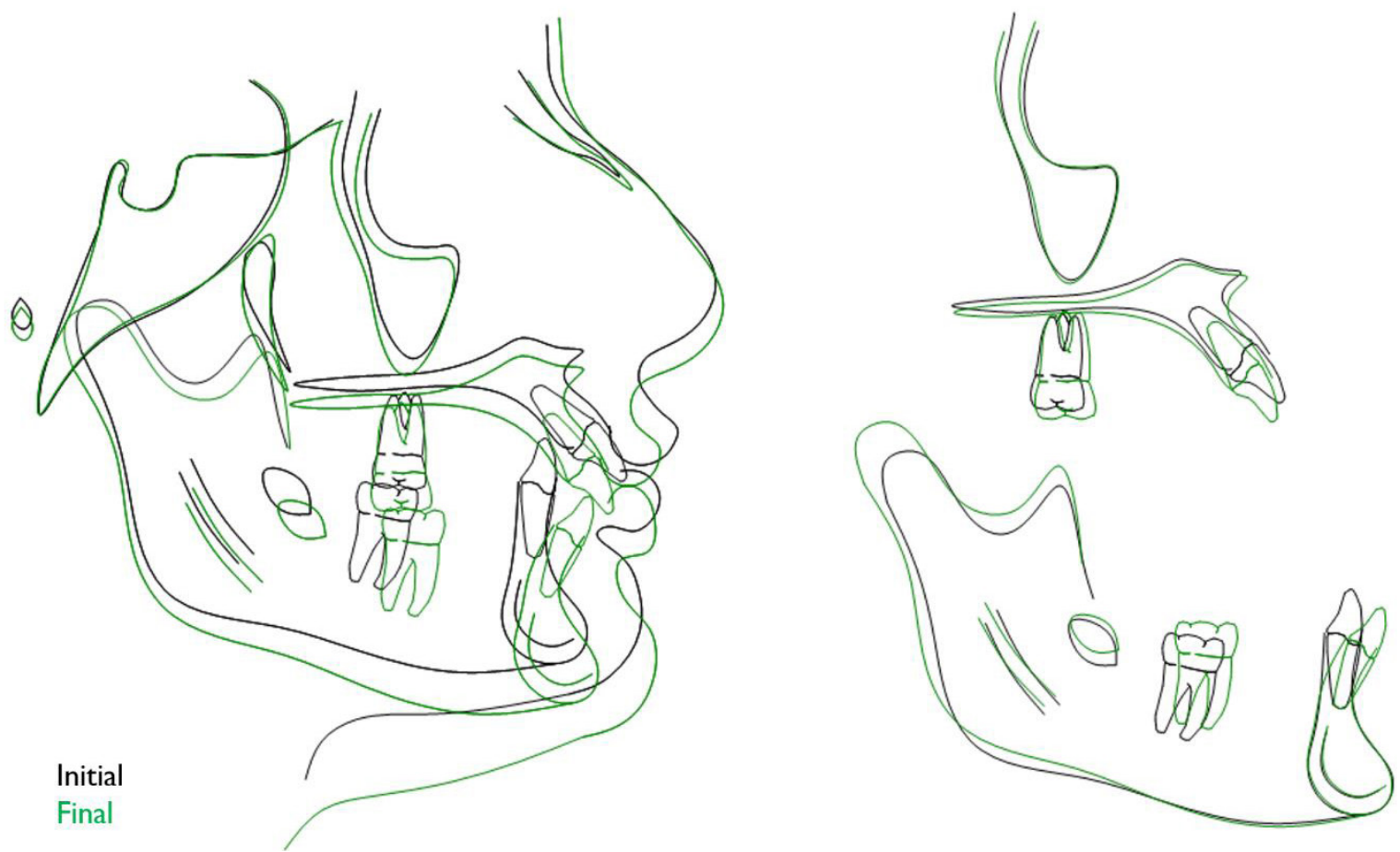

Figure 7. Cephalometric superimpositions of the initial and final cephalometric radiographs 
9. Faxén Sepanian V, Sonnesen L. Incisor root resorption in Class II division 2 patients in relation to orthodontic treatment. Eur J Orthod. 2018; 40(3): 337-42. doi:10.1093/ejo/cjx086.

10. Franchi L, Baccetti T. Prediction of individual mandibular changes induced by functional jaw orthopedics followed by fixed appliances in Class II patients. Angle Orthod. 2006; 76(6): 950-4. doi:10.2319/110205-385.

11. Cozza P, Baccetti T, Franchi L, De Toffol L, McNamara JA. Mandibular changes produced by functional appliances in Class II malocclusion: A systematic review. Am J Orthod Dentofac Orthop. 2006; 129(5): 599.e1-12. doi:10.1016/j.ajodo.2005.11.010.

12. O'Brien K, Wright J, Conboy F, et al. Effectiveness of treatment for Class II malocclusion with the Herbst or Twin-block appliances: A randomized, controlled trial. Am J Orthod Dentofac Orthop. 2003; 124(2): 128-37. doi:10.1016/S08 89-5406(03)00345-7.

13. Banks $P$, Wright J, O'Brien $\mathrm{K}$. Incremental versus maximum bite advancement during twin-block therapy: A randomized controlled clinical trial. Am J Orthod Dentofac Orthop. 2004; 126(5): 583-8. doi:10.1016/j.ajodo.2004.03.024.

14. Guo Y, He S, Gu T, Liu Y, Chen S. Genetic and clinical risk factors of root resorption associated with orthodontic treatment. Am J Orthod Dentofac Orthop. 2016; 150(2): 283-9. doi:10.1016/j.ajodo.2015.12.028.

15. Renkema AM, Fudalej PS, Renkema A, Bronkhorst E, Katsaros C. Gingival recessions and the change of inclination of mandibular incisors during orthodontic treatment. Eur J Orthod. 2013; 35(2): 249-55. doi:10.1093/ejo/cjs045.

16. Renkema AM, Navratilova Z, Mazurova K, Katsaros C, Fudalej PS. Gingival labial recessions and the post-treatment proclination of mandibular incisors. Eur J Orthod. 2015; 37(5): 508-13. doi:10.1093/ejo/cju073.

17. Balut N, Hansa I, González E, Ferguson DJ. Bone regeneration after alveolar dehiscence due to orthodontic tooth movement - A case report. APOS Trends Orthod. 2019; 9: 117. doi:10.25259/APOS-75-2019.

18. Kao RT, Curtis DA, Kim DM, et al. American Academy of Periodontology best evidence consensus statement on modifying periodontal phenotype in preparation for orthodontic and restorative treatment. J Periodontol. 2020; 91(3): 289-98. doi:10.1002/JPER.19-0577.

19. Sameshima GT, Sinclair PM. Predicting and preventing root resorption: Part I. Diagnostic factors. Am J Orthod Dentofac Orthop. 2001; 119(5): 505-10. doi:10.1067/mod.2001.113409.

20. Justus R. Prevention of external apical root resorption during orthodontic treatment. Clin Dent Rev. 2018; 2(1): 1-6. doi:10.1007/s41894-018-0035-3. 